http://jmscr.igmpublication.org/home/ ISSN (e)-2347-176x ISSN (p) 2455-0450 crossref DOI: https://dx.doi.org/10.18535/jmscr/v7i11.17

\title{
Outcome \& Effect of Coronary Artery Bypass Graft Surgery on Left Ventricular Systolic Function: A Descriptive Study
}

\author{
Authors \\ Dr Nareshchand Hegde $\mathbf{H}^{1}$, Dr Syed Faizan ${ }^{2}$, Dr Rajiv Girdhar ${ }^{3}$, Dr Pranay Mittal ${ }^{4}$ \\ ${ }^{1}$ Associate Professor in CTVS) Rajarajeswari Medical College \& Hospital \\ ${ }^{2}$ Post Graduate in General Surgery) Rajarajeswari Medical College \& Hospital \\ ${ }^{3}$ Assistant Professor in Cardiology Dept., Rajarajeswari Medical College \& Hospital, \\ ${ }^{4}$ Post Graduate in General Medicine, Rajarajeswari Medical College \& Hospital, \\ Kambipura, Mysore Road, Bangalore 560074, India
}

\begin{abstract}
Background and Objectives: Patients with low ejection fraction $(E F)$ are at high risk for postoperative complication and mortality. Our Aim: outcome \& effect of coronary artery bypass graft surgery on left ventricular systolic function.

Materials and Methods: This is a descriptive study. Between January 2017 to August 2019, 51 consecutive patients underwent isolated $C A B G$ at the Rajarajeshwari medical college and Hospital. Of these, 51 had echocardiographic assessment of LV function, preoperatively with respect to patient characteristics, risk factors, and preoperative two dimension echocardiography (2D ECHO). Depending on findings of 2D ECHO patients were divided into three groups: in Group 1, we included patients with EF 30\%-35\%, Group 2 comprised patients with EF of 25\%-30\%, and Group 3 consisted of patients with EF. Appropriate investigations were done.

Results: Hospital mortality rate in present series was $9.8 \%$. Mean grafts were 3.02 per patient. Fourteen (40\%) patient had a postoperative complication. EF improved in $78 \%$ of patients. Canadian Cardiovascular Society Angina class improved in $42 \%$ of patients.

Conclusion: We have shown that cardiac surgery provides long-term cardiac-death-free survival benefit in patients of all subsets of LV function, including poor and very poor LV function.

Keywords: $C A B G$ (Coronary artery bypass surgery), low ejection fraction $(E F)$, stunned myocardium.
\end{abstract}

\section{Introduction}

Coronary artery revascularization via coronary artery bypass grafting (CABG) is indicated for patients with angina and suitable coronary anatomy, especially those with stenosis of the left main coronary artery or patients with left main equivalent disease $^{(1-5)}$. Patients with low EF are at higher risks of sudden death, ventricular arrhythmia, and worsening heart failure due to recurrent ischemia. ${ }^{[5,6]}$ Left ventricular dysfunction in patients with coronary artery disease is not always an irreversible process related to previous myocardial infarction since left ventricular function improves substantially in many patients and may even normalize after coronary artery bypass grafting. ${ }^{[7]}$ In these patients with low EF, coronary artery bypass grafting has been shown to be superior to medical therapy 
alone, resulting in significant clinical improvement and improving long-term survival. ${ }^{[8]}$ Advances in preoperative management, refinements in surgical techniques, use of off-pump coronary artery bypass grafting, and advances in cardiac anesthesia with improvement in intensive postoperative care all have resulted in a decrease in the mortality rate in patients with low EF operated by off-pump coronary artery bypass surgery.

The purpose of this study was to evaluated the outcome of patients with coronary artery disease with low EF with respect to long-term survival, mortality, complications, improvement in EF, and quality of life.

\section{Aims \& Objectives}

To assess the effect of low EF on clinical outcome after surgery.

\section{Materials \& Methods}

This study was conducted in the Rajarajeshwari Medical College \& Hospital, Mysore road, Bangalore. It was a hospital based observational descriptive study and was carried out from January 2016 to August 2019. All 51 patients of coronary artery disease with low EF, operated in our center, by coronary artery bypass grafting during a 3.6-year period (2016-2019), were included in this study. After admission for coronary artery bypass grafting, detailed history recording, clinical examination, and relevant investigations were carried out. History included past episodes of myocardial infarction, thrombolytic medication if any in the past, comorbidity, and personal history regarding addiction to alcohol and tobacco. One patient had a history of coronary angioplasty done in 2011 and presented with stent block and critical triple vessel disease. Another patient was with single vessel disease, in which cardiologist had tried stenting, but since stent could not be negotiated due to tight stenosis was referred for surgery. All patients were investigated with respect to kidney function test, liver function test, creatinine
phosphokinase-MB

(CPK-MB),

and two-dimensional echocardiography (2D ECHO). We operated only those patients with CPK-MB within normal range. $\mathrm{EF}$ was determined by calculation with 2D-ECHO through the biplane apical method and modified Simpson's rule. We categorized those patients with low EF, The categories were EF $31 \%-35 \%$, EF $25 \%-30 \%$, and $\mathrm{EF}<25 \%$. All those patients, whose $\mathrm{EF}$ was $<25 \%$, are further evaluated for myocardial viability by thallium scanning.

\section{Results}

Table 1: Characteristics of the study participants $(n=51)$

\begin{tabular}{|l|c|}
\hline Characteristic & $\boldsymbol{n ( \% )}$ \\
\hline Male & $\mathbf{4 1}(\mathbf{8 0 . 4 )}$ \\
\hline Female & $\mathbf{1 0 ( 1 9 . 6 )}$ \\
\hline Mean age (years) & 54.66 \\
\hline Triple vessel disease & $40(78.4)$ \\
\hline Double vessel disease & $6(11.7)$ \\
\hline Single vessel disease & $5(9.8)$ \\
\hline $\begin{array}{l}\text { History of acute myocardial } \\
\text { infarction }\end{array}$ & $44(86.2)$ \\
\hline History of thrombolysis & $21(41.1)$ \\
\hline Class I angina & $20(39.2)$ \\
\hline Class II angina & $29(56.8)$ \\
\hline Class III angina & $2(3.9)$ \\
\hline History of diabetes & $32(52.7)$ \\
\hline History of hypertension & $23(45)$ \\
\hline Ejection fraction $(\%)$ & $24(47)$ \\
\hline $31-35$ & $19(37.2)$ \\
\hline $25-30$ & $8(15.8)$ \\
\hline$<25$
\end{tabular}

Table1 revealed- history of smoking was present in $27(52.9 \%)$ patients. History of chronic obstructive pulmonary disease was present in four patients. History of peripheral vascular disease was present two patients. Eight (15.56\%) patients gave a history of alcoholism. Seven (13.7\%) patients gave a history of both smoking and alcoholism. Other laboratory investigations of these patients were normal except for high values of kidney function test in three patients with diabetes mellitus. All patients depending on estimated EF by 2D ECHO were divided into three groups. Group I - EF: 31\%-35\% included $24(47 \%)$ patients, Group II - EF: 25\%-30\% 19 patients $(37.2 \%)$, and Group III - EF: $<25 \% 8$ patients $(15.8 \%)$. Four patients of Group III were 
treated successfully with coronary artery bypass grafting. All those patients, whose EF was $<25 \%$, were further evaluated by positron emission tomography thallium scan. Three out of Six patients show no peri- infarct viability in right coronary artery territory and other in left circumflex artery territory artery. Both patients died postoperatively. We planned those patients for coronary artery bypass surgery who were hemodynamically stable and fit for anesthesia. In our setup, we prefer off- pump coronary artery bypass grafting in all patients except those who showed hemodynamic deterioration after lifting up heart, underwent on- pump beating heart surgery. Thus, Four patients $(8.5 \%)$ were done on- pump beating heart surgery and 47 patients (91.5\%) were off- pump beating heart surgery. Left internal mammary artery was harvested in 47 patients $(91.5 \%)$ but used as a conduit in 43 patients $(84.3 \%)$. In one patient, it was of very poor caliber and flow, and in other patient, there was intimal flap dissection. Thus, in those patients, great saphenous vein was used as conduit. Radial artery was used as a conduit in Four patients (7.8\%). Reverse great saphenous vein graft was used as a conduit in all patients. A total number of grafts in our study were 150, and an average number of grafts per patient were 2.942. Some patients mainly with diabetes mellitus had diffuse nongraftable coronary arteries. Eight (15.6\%) patients required IABP support. In Three patients, intra- aortic balloon insertion (IABP) was done immediately before closure of sternum and in Five patients postoperatively. Out of these six patients, five patients did not survive the procedure. Of the one who survived, one died due to septicemia 14 days postoperatively.

Table 2: Postoperative complications

\begin{tabular}{|l|c|}
\hline Event & $\boldsymbol{n}(\boldsymbol{\%})$ \\
\hline Death & $5(9.8)$ \\
\hline Sternal Instability & $1(1.9)$ \\
\hline Left- sided hemithorax & $2(3.9)$ \\
\hline Ventricular fibrillation & $1(1.9)$ \\
\hline Postoperative myocardial infarction & $2(3.9)$ \\
\hline Atrial fibrillation & $1(1.9)$ \\
\hline
\end{tabular}

\section{Postoperative Complications}

Table 2 revealed there were $5(9.8 \%)$ mortalities in this study group. Two patient was with EF $35 \%$ operated by on-pump beating heart surgery; this patient deteriorated even after insertion of IABP and went in low cardiac output state. Three patients develop renal failure postoperatively. Other patient was 70 years diabetic male patient who had low cardiac output and respiratory failure. He eventually develops septicemia and succumbed. Total 10 (19.6\%) patients had a postoperative complication. One patient had sternal instability and was operated by sterna rewiring. Two (3.9\%) patients were reexplored for left- sided hemothorax. One patient had complication of ventricular fibrillation with prior ECG changes of acute myocardial infarction. Two patients had a postoperative myocardial infarction. One patient developed atrial fibrillation. One patient had sudden cardiac arrest, after intracardiac massage and IABP support, he could be revived. A mean hospital stay of all these patients was 11.2 days.

\section{Postoperative Follow-Up}

All patients were followed for 1.5 years. Four out of 51 surviving patients were lost to follow-up. All patients were examined regarding any residual symptoms and with respect to Canadian Cardiovascular Society Angina Classification. Twenty nine $(56.8 \%)$ patients had no symptom of angina. Three patients had mild chest discomfort. Six $(30 \%)$ patients who initially had Class 2 angina now presented with Class 1 angina. Two patients had severe chest pain but was hemodynamically stable. ECG shows no fresh ST, $\mathrm{T}$ wave changes. All patients were reassessed by 2D ECHO to evaluate EF. Out of the three patients with low $\mathrm{EF}<25 \%$, one showed improvement in EF to $35 \%$ while the other Three improved to $40 \%$. Others also showed improvement in EF up to $40 \%$ in $40(78.4 \%)$ and $45 \%$ in $8(15.6 \%)$. Thus, there was definitely increase in EF in patients who were successfully operated. 


\section{Discussion}

Coronary artery bypass grafting enables longer survival and better quality of life than does the medical therapy. ${ }^{[9]}$ The patient with low EF, as studied from 2D- ECHO findings, had regional wall motion abnormalities, with hypokinesia or akinesia. Thus, in patients of left ventricular dysfunction in the presence of stunned myocardium, after revascularization, there is return of viable myocardium, improvement in EF which provides relief of symptom and offer survival $>60 \%$ at more than 5 years. ${ }^{[10]}$ The other predictor of outcome of these patients is operative technique. With the use of conventional on- pump surgery which is associated with release of inflammatory mediators and potential induction of multiple organ dysfunction, with significant myocardial edema and ischemia, which further depresses myocardial function resulting in high mortality and morbidity. Hence, on- pump coronary artery bypass grafting is not the solution for patients with low $\left.\mathrm{EF}^{[10}\right]$ In a study performed by Rastan et al. using on- pump beating heart surgery among patients with normal EF, they found increase incidence of myocardial injury when compared to off-pump surgery. ${ }^{[11]}$ In the present study, we used off- pump coronary artery bypass grafting in $47(91.5 \%)$ of patients. There was no technical difficulty with acceptable mortality rate. Mortality rate in the present study was $11 \%$. Di Carli et al. had operative mortality of 9.3\% in patient with low EF. ${ }^{[11]}$ Christakis et al. recorded operative mortality of $9.8 \%$ with an EF of $<20 \% .{ }^{[9]}$ Carr et al. reported $11 \%$ perioperative mortality rate. ${ }^{[10]}$ In the present study, there was no difficulty while grafting obtuse marginal artery and posterior descending artery, due to availability of suction stabilizer and positioner, and hence no compromise with revascularization. In the present study, mean grafts were 4 per patient comparable with Di Carli et al. study which also reported mean grafts of 3 per patient. ${ }^{[12]}$ Number of complications was also less in the present study. During follow- up of patients, symptoms of angina were significantly decreased further improving the quality of life. Thus, in patients of left ventricular dysfunction in the presence of stunned myocardium, after revascularization, there is return of viable myocardium to normal functional state and increase in EF as seen with all our patients.

\section{Conclusion}

Using this large database of patients over a long period of practice of one surgeon, we have shown that with coronary artery disease and low EF off- pump, CABG can be performed relatively safely and is a safe procedure. It results in good medium- term survival, improves left ventricular function, and enhances overall quality of life.

Conflict of interest: none declared.

\section{References}

1. Yancy CW, Jessup M, Bozkurt B, et al. 2013 ACCF/AHA guideline for the management of heart failure: a report of the American College of Cardiology Foundation/American Heart Association Task Force on Practice Guidelines. J Am Coll Cardiol 2013;62:e147-239. 10.1016/j.jacc.2013.05.019 [PubMed] [CrossRef] [Google Scholar]

2. Hillis LD, Smith PK, Anderson JL, et al. 2011 ACCF/AHA Guideline for Coronary Artery Bypass Graft Surgery: executive summary: a report of the American College of Cardiology Foundation/American Heart Association Task Force on Practice Guidelines. Circulation 2011;124:2610-42.

10.1161/CIR.0b013e31823b5fee

[PubMed] [CrossRef] [Google Scholar]

3. Levine GN, Bates ER, Blankenship JC, et al. 2011 ACCF/AHA/SCAI Guideline for Percutaneous Coronary Intervention: executive summary: a report of the American College of Cardiology Foundation/American Heart Association Task Force on Practice Guidelines and the 
Society for Cardiovascular Angiography and Interventions. Circulation 2011;124: 2574-609. 10.1161/CIR.0b013e31823a 5596 [PubMed] [CrossRef] [Google Scholar]

4. Fihn SD, Gardin JM, Abrams J, et al. 2012 ACCF/AHA/ACP/AATS/PCNA/SCAI/ST $S$ guideline for the diagnosis and management of patients with stable ischemic heart disease: a report of the American College of Cardiology Foundation/American Heart Association task force on practice guidelines, and the American College of Physicians, American Association for Thoracic Surgery, Preventive Cardiovascular Nurses Association, Society for Cardiovascular Angiography and Interventions, and Society of Thoracic Surgeons. Circulation 2012;126:e354-471. 10.1161/CIR. 0b013e

318277d6a0 [PubMed] [CrossRef]
[Google Scholar]

5. Caracciolo EA, Davis KB, Sopko G, et al. Comparison of surgical and medical group survival in patients with left main equivalent coronary artery disease. Longterm CASS experience. Circulation 1995; 91:2335-44. 10.1161/01.CIR.91.9.2335 [PubMed] [CrossRef] [Google Scholar]

6. Kunadian V, Zaman A, Qiu W. Revascularization among patients with severe left ventricular dysfunction: A meta-analysis of observational studies. Eur J Heart Fail 2011;13:773-84.

7. Elefteriades JA, Tolis G Jr., Levi E, Mills LK, Zaret BL. Coronary artery bypass grafting in severe left ventricular dysfunction: Excellent survival with improved ejection fraction and functional state. J Am Coll Cardiol 1993;22:1411-7.

8. Scott SM, Deupree RH, Sharma GV, Luchi RJ. VA Study of Unstable Angina 10 -year results show duration of surgical advantage for patients with impaired ejection fraction. Circulation 1994;90(5 Pt 2):II120-3.

9. Christakis GT, Weisel RD, Fremes SE, Ivanov J, David TE, Goldman BS, et al. Coronary artery bypass grafting in patients with poor ventricular function. Cardiovascular Surgeons of the University of Toronto. J Thorac Cardiovasc Surg 1992;103:1083-91.

10. Carr JA, Haithcock BE, Paone G, Bernabei AF, Silverman NA. Long-term outcome after coronary artery bypass grafting in patients with severe left ventricular dysfunction. Ann Thorac Surg 2002;74:1531-6.

11. Rastan AJ, Bittner HB, Gummert JF, Walther T, Schewick CV, Girdauskas E, et al. On-pump beating heart versus offpump coronary artery bypass surgeryevidence of pump-induced myocardial injury. Eur J Cardiothorac Surg 2005;27:1057-64.

12. Di Carli MF, Maddahi J, Rokhsar S, Schelbert HR, Bianco- Batlles D, Brunken $\mathrm{RC}$, et al. Long- term survival of patients with coronary artery disease and left ventricular dysfunction: Implications for the role of myocardial viability assessment in management decisions. $\mathbf{J}$ Thorac Cardiovasc Surg [1998;116:997-1004]. 